
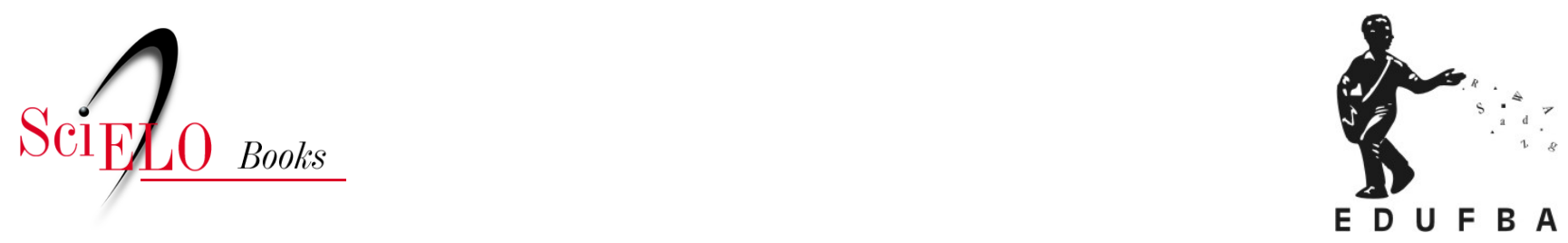

\title{
Pensar por pluralidades
}

\author{
Josianne Francia Cerasoli
}

CERASOLI, J.F. Pensar por pluralidades. In: JACQUES, P.B., and PEREIRA, M.S., comps. Nebulosas do pensamento urbanístico: tomo I-modos de pensar [online]. Salvador: EDUFBA, 2018, pp. 262-287. ISBN 978-85-232-2032-7. https://doi.org/10.7476/9788523220327.0011.

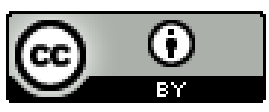

All the contents of this work, except where otherwise noted, is licensed under a Creative Commons Attribution 4.0 International license.

Todo o conteúdo deste trabalho, exceto quando houver ressalva, é publicado sob a licença Creative Commons Atribição 4.0. 
PENSA R PO R 


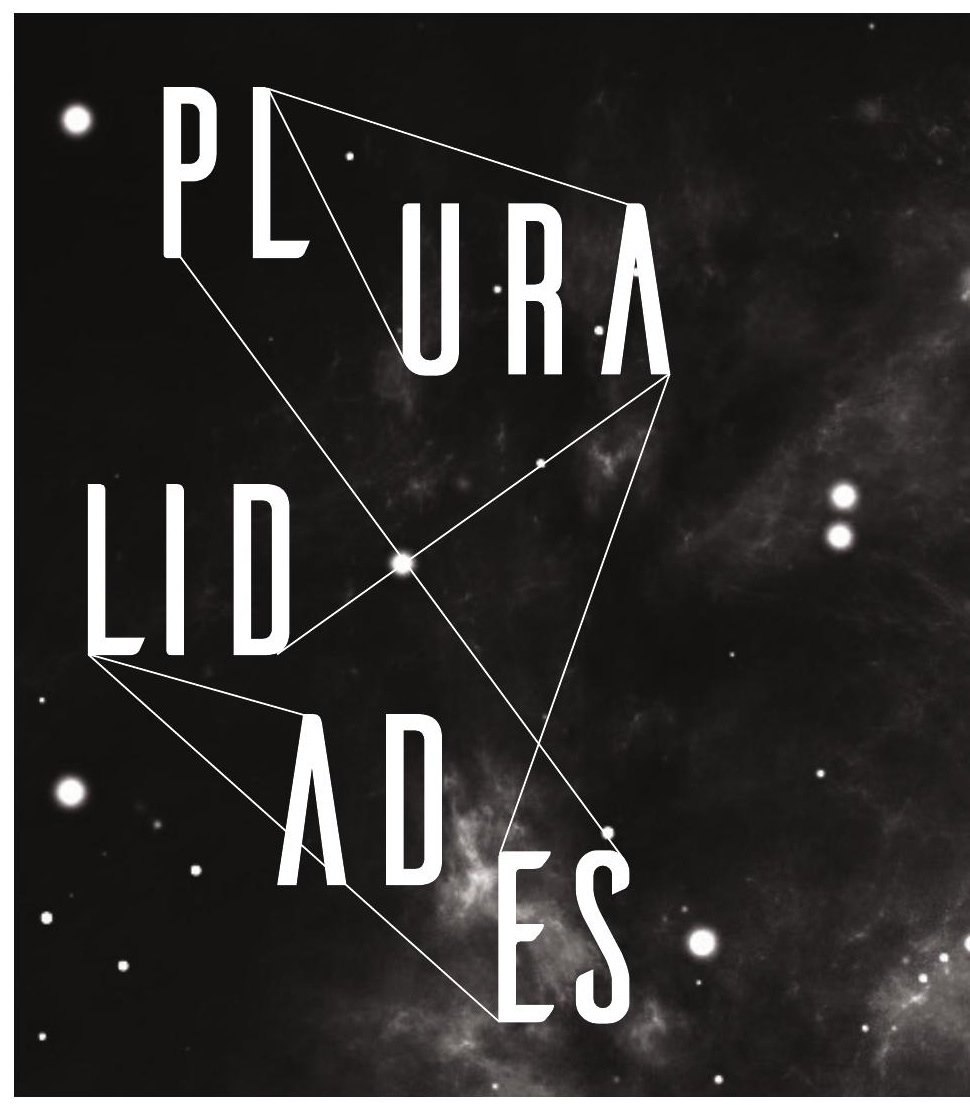




$$
\begin{aligned}
& P E N S \wedge R \\
& \text { P O R } \\
& P L U A \Lambda L I D \Lambda D E S
\end{aligned}
$$

Pluralidades, cidades

$$
\begin{aligned}
& \text { JOSI AN NE } \\
& \text { FRANC I A } \\
& \text { CERASOLL }
\end{aligned}
$$


Ao egoísmo pode ser oposto apenas o pluralismo, isto é, o modo de pensar que consiste em não se considerar nem em proceder como se o mundo inteiro estivesse encerrado no próprio eu, mas como um simples cidadão do mundo.

(KANT, 1798, p. 30)

A pluralidade humana, condição básica da ação e do discurso, tem o duplo aspecto da igualdade e da diferença. Se não fossem iguais, os homens seriam incapazes de compreender-se entre si e aos seus ancestrais, ou de fazer planos para o futuro e prever as necessidades das gerações vindouras. Se não fossem diferentes [...], os homens não precisariam do discurso ou da ação para se fazerem entender.

(ARENDT, 2004, p. 188)

1 idade", substantivo plural. Segundo os dicionários, "plural", um adjetivo de dois gêneros, remete ao variado, ao múltiplo, sendo antítese de singular. "Pluralidade", qualidade do plural, contemplaria, assim, o existir em grande quantidade, caracterizado pela não unicidade. Nos dois termos, o antepositivo "plur(i)" é herdeiro inequívoco do latim "plus, pluris", "mais, maior", de significado conexo a "miria”, "multi", "pleto", "poli” e origem de uma série de noções, como pluriforme, plurívoco, pluralismo, pluralizar, plurivalente. 
Definida como uma aglomeração humana com numerosas edificações, mesmo quando as descrições se limitam à materialidade e a seus fins, a cidade é reiteradamente flexionada no plural, como espaço edificado de modo a favorecer ações diversas da vida humana: moradia, comércio, atividades culturais, financeiras, administrativas, mercantis, industriais ou produtivas, em geral, não agrícolas. A dimensão plural é ainda reforçada quando considerada em sua abrangência social - "a primeira das grandes sociedades de várias famílias”, segundo verbete da Encyclopédie (DIDEROT; D'ALEMBERT, 2006, p. 47) - e sua função política, como civitas, burgo, vila, sede episcopal ou base do controle do território, como se destaca ao se abordar a instalação de cidades na América sob domínio ibérico. ${ }^{1}$ Todas essas dimensões, materiais, sociais, políticas, consideradas historicamente, ainda multiplicam a pluralidade da cidade, mesmo quando priorizamos o conceito e não as milhões de ocorrências de urbes desigualmente distribuídas pelo mundo. Cidades, pluralidades.

Nas duas epígrafes provenientes de tradições importantes do pensamento filosófico, são assumidas dimensões éticas e políticas no entendimento da pluralidade. No final do século XVIII, ao definir filosoficamente a faculdade de conhecer, Kant (2006) sublinha o pluralismo como uma postura, "um modo de estar no mundo", uma ética ao mesmo tempo distanciada de um mero autoreferenciamento e direcionada a um imaginado cosmopolitismo, a uma disponibilidade para pensar com referências plurais, como um "cidadão do mundo". ${ }^{2}$ Kant tem sido referenciado como um dos primeiros a sistematizar ideias a respeito do pluralismo na filosofia, embora se perceba o paulatino afastamento em relação à ideia kantiana dessa oposição ao egoísmo, assumindo-se significados mais próximos ao acolhimento da diversidade, ou uma postura ético-filosófica que admite no mundo uma pluralidade simultânea de elementos. Contemporaneamente, a noção se associa ao reconhecimento da possibilidade de avaliações e interpretações diversas da mesma situação, desdobrando-se em um importante princípio presente em sociedades democráticas quando a postura assume a possibilidade de considerar defensáveis diferentes perspectivas e visões de mundo, como fundamento, por exemplo, 266 da defesa da tolerância. 
Não menos controverso seria o percurso do pensamento político que repercute as reflexões contundentes de Hannah Arendt, em meados do século XX, afastando-se de uma suposta definição universal da humanidade para ater-se às condições de humanidade, nas circunstâncias definidoras do humano, sobretudo aquelas profundamente alteradas pela própria modernidade, segundo a autora. A pluralidade está entre os cinco conceitos-chave mobilizados por Arendt (2004, p. 15) para expressar a condição humana, junto a natalidade, mortalidade, mundanidade e terra. Pluralidade, para a autora, condição sine qua non e conditio per quam de toda a vida política, é, a um só tempo, decisiva para o homem e a própria essência da política, condição humana por definição. A ação, única atividade exercida entre os homens sem mediação das coisas, corresponde à condição humana da pluralidade. Associada à diferença, a pluralidade equivale não à alteridade, mas à capacidade humana de exprimir essa diferença e distinguir-se: só o homem "é capaz de comunicar a si próprio e não apenas comunicar alguma coisa”, afirma Arendt (2004, p. 189). Essa distinção vem à tona no discurso e na ação, e, a partir deles, são estabelecidas as teias de relações humanas, historicamente.

Ao se aproximar investigações sobre a cidade e apontamentos filosóficos em torno da pluralidade, sobretudo em investigações norteadas por perspectivas históricas, não será difícil delinear dimensões similares ou coincidentes com noções mobilizadas até aqui. Elementos como a multiplicidade, a postura pluralista, a relevância da ação e o discurso, ou seja, do encontro de diferenças, a vida política em si, têm sido todas dimensões direta ou indiretamente relacionadas à cidade. Talvez a síntese mais instigante nesse sentido possa ser localizada nas assertivas de Aristóteles, no século IV a.C., justamente na obra Política, ao abordar a impossibilidade de se fazer existir a cidade a partir de indivíduos iguais, dada a fundamental importância da dessemelhança na constituição da pólis. Ao analisar as origens e causas das associações humanas em meio a investigações em torno do que chamaria de uma filosofia prática, Aristóteles aprofunda o entendimento ético da pólis, assinalando as virtudes esperadas para os cidadãos na busca racional da autorrealização, segundo afirma, fim último da pólis somente possível em sociedade. (GOMES, 2013) Ao pescrutrar as supostas virtudes do bom cidadão, distingue-as 
daquelas do indivíduo, assumindo a necessária composição da pólis por dessemelhantes, não por indivíduos iguais (livro III, 1276b a 1277). ${ }^{3}$

A pluralidade, portanto, seria condição mesma da cidade, localizando-se no centro de suas atividades, definindo-a como fenômeno humano e político singular. Essa dimensão plural é característica distintiva da cidade quando nomeada como urbe, aglomeração humana oposta ao campo; como civitas, que remete à cidadania exercida na cidade; ou pólis, assinalando uma sociedade ou cidade-estado caracterizada por um senso de pertencimento ou comunidade. Caberia, portanto, indagar a respeito do lugar da pluralidade, característica essencial, decisivamente presente nas diferentes dimensões e definições em torno da cidade, nos estudos sobre a cidade. Seria oportuno, pois, considerar o papel da pluralidade não apenas como aspecto a ser descrito, a ser investigado em distintos desdobramentos e especificidades, mas também como perspectiva fundamental para se examinar a cidade, para estudá-la a partir de questões igualmente plurais, ainda que essa característica possa torná-la inapreensível a partir de um único ponto de vista.

Essas considerações gerais acerca de dimensões da pluralidade e da oportuna apreensão plural da cidade norteiam os apontamentos com os quais busco responder à provocação trazida por esta coletânea: pensar a cidade "por pluralidades". Busco tecer algumas reflexões sobre a impossibilidade de se abarcar o urbano como um conjunto ou ainda a dificuldade de se compreender seus significados e desafios sem considerar a dimensão plural - paradoxalmente, uma singularidade do urbano. Coloco em pauta essa importância tomando por guias, nesta breve reflexão, alguns modos da pluralidade nos estudos urbanos: como modo de pensar e conhecer ou como uma abordagem, como dinâmica política intrínseca ao urbano e como possibilidade de discussão de uma provável condição cosmopolita, de algum modo associada ao urbano. Para isso, abordo inicialmente um panorama sobre "perspectivas pluralistas" relativas ao conhecimento para discutir alguns riscos da homogeneidade na adoção de pressupostos teóricometodológicos em investigações sobre a cidade; analiso algumas abordagens, sobretudo relativas à cidade no continente americano; pontuo algumas potencialidades ao se investigar pluralidades e lidar 268 com referências também plurais. Em todo o percurso, meu ponto de 
observação está norteado pela reflexão histórica e historiográfica, campo a partir do qual problematizo o urbano como objeto de pesquisa.

\section{Pluralidade, Pressupostos, enduadramentos}

Ainda se fosse possível supor a total estabilidade dos aportes teóricos e dos próprios sistemas de conhecimento para, mesmo que apenas para um exercício do pensamento, por hipótese ou efeito heurístico, constituir uma base conceitual consistente ou inabalável para apreender o urbano, seria incontornável a consideração da pluralidade de saberes mobilizados para tanto. Mesmo diante de alguma improvável base estável para o conhecimento sobre a cidade, a consideração dos diferentes saberes voltados a seu estudo, diagnóstico e intervenção impõe de saída ao menos justificar escolhas prévias entre diferentes campos - da economia, da política, da economia política, da sociologia, da antropologia, da psicologia, da geografia, da ecologia, da engenharia, do urbanismo, da filosofia, das artes, da história etc. Sem se tomar esses distintos campos do conhecimento em perspectiva histórica, que obrigatoriamente traria à pesquisa o desafio maior de considerar as dinâmicas e relações instáveis entre os diferentes saberes, a pluralidade dos pressupostos mobilizados para apreensão do urbano mostra-se como condição inicial para todo estudo voltado a compreendê-lo. Seria plausível argumentar ser essa uma condição praticamente obrigatória para qualquer temática inscrita na história humana, mas me parece especialmente sensível considerá-la nos estudos sobre a cidade, sobretudo levando-se em conta a demanda desafiante pela organização da vida urbana reiterada cotidianamente.

Que saberes seriam inqueridos diante dos desafios renovados nas cidades, especialmente nos últimos 200 anos, quando a densidade populacional e a complexidade das imbricações e dos problemas associados aos modos de vida urbanos consolidaram a permanência da chamada "questão urbana", em suas distintas dimensões? Presente na pauta de diferentes campos do conhecimento e numerosas expressões das artes, a cidade tomada como uma questão pode ser entendida tanto como motivação ou origem para determinadas áreas ou saberes, como diretamente aponta as trajetórias do urbanismo, quanto como 
incitação ao aperfeiçoamento de certos referenciais e conhecimentos, como a antropologia ou a psicologia urbanas, por exemplo.

Parece-me significativo considerar, entre outros, alguns estudos em torno do urbano que podem ser tomados como pioneiros, como iniciadores de certas abordagens da questão, como os levantamentos de Engels (2008) sobre as condições degradantes de moradia dos trabalhadores na Manchester industrial; os estudos de Gustave Le Bon (2008) sobre a psicologia das multidões, no final do século XIX; as sensíveis reflexões de Simmel (2005) sobre os efeitos da vida monetária para os habitantes das grandes cidades; e os instigantes trabalhos de Benjamin (2007) sobre aspectos simultâneos e múltiplos das mudanças na vida da metrópole, sobretudo em Paris, já no início do século seguinte. ${ }^{4}$ Para cada um deles, individualmente, bem como para uma provável avaliação de conjunto que se pudesse extrair de trabalhos como esses, é possível acompanhar tópicos inter-relacionados, todos ligados ao urbano e capazes de apontar a configuração de temáticas variadas a partir de percepções de mudanças nas formas de organização humanas nas cidades.

A prioridade das análises nesses estudos pioneiros não está, de modo geral, na materialidade da cidade, embora seja nela um elemento de grande relevância. Ainda que esteja presente, a análise dos aspectos materiais e formais da cidade aparece entremeada por questões políticas e sociais, como em Engels e Le Bon, principalmente, ou perpassada por aspectos sensíveis, relativos a mudanças de modos de percepção da vida urbana, em Simmel e Benjamin. A relevância dos estudos simmelianos, inclusive seus desdobramentos na configuração do campo da sociologia, sobretudo nos Estados Unidos, e das reflexões benjaminianas, também na expressiva recepção à obra no Brasil, estimulam um olhar um pouco mais detido sobre ambos para se pensar por pluralidades. São duas obras cuja interface nos estudos urbanos, em especial nas humanidades, tem estimulado análises plurais sobre a cidade, além de estabelecerem importantes balizas para pautar investigações sob distintos aspectos.

A despeito da dificuldade de se descrever uma objetiva recepção à obra 270 Georg Simmel no Brasil, segundo levantamento de Waizbort (2007), a 
presença das reflexões do sociólogo berlinense pode ser acompanhada em diversos autores, desde pelo menos os anos 1930, com Fernando de Azevedo, em seus Princípios de Sociologia, acentuando nos anos 1960, a partir dos trabalhos do antropólogo Gilberto Velho sobre individualismo e cultura. Parece ser nesse movimento que as discussões de Simmel acerca dos efeitos das dinâmicas urbanas na vida dos indivíduos na contemporaneidade encontram maior eco entre os estudiosos no Brasil, assinalando a inserção nesses estudos da análise sobre a vida nas grandes cidades, originalmente traduzido a partir da versão em inglês de 1935 como "Metrópole e vida mental", na importante coletânea organizada por Otávio Guilherme Velho (1967). ${ }^{5}$ A sensível reflexão do sociólogo alemão, baseada em seu abrangente estudo sobre o fenômeno histórico do dinheiro, Filosofia do dinheiro (1900-1907), tem sido referência fundamental para os estudos em torno da cultura urbana. Preparado especialmente para a Exposição Municipal Alemã ocorrida em Dresden, em 1903, posteriormente traduzido no Brasil como "A grande cidade e a vida do espírito" (2005), o estudo analisa os fundamentos psicológicos sobre os quais se eleva a individualidade na grande cidade, ao lado da intensificação do que denomina "vida nervosa", configurada por mudanças rápidas de impressões interiores e exteriores nos habitantes da cidade. (SIMMEL, 2005, p. 578)

A ênfase desse estudo coloca-se justamente nos efeitos psicológicos, subjetivos, intelectuais da vida urbana sobre seus moradores, e só é possível hoje deduzir a inserção dessa discussão sobre temas que poderiam ser vistos como pouco objetivos na extensa pauta de questões relativas ao urbano abordadas na Exposição de Dresden. Segundo Howard Woodhead (1904a), sociólogo da Universidade de Chicago, correspondente de Simmel nos Estados Unidos no período, os temas abordados na exposição buscavam apresentar um panorama das condições das municipalidades alemãs no início do século, bem como a produção industrial destinada ao uso da municipalidade. Em uma série de artigos publicados no American Journal of Sociology, Woodhead (1904a, 1904b, 1904c) detalha e comenta cada um dos temas abordados no evento, tais como o tráfego, a expansão urbana, a questão da moradia, a caridade pública, saúde pública, educação, arte pública, finanças e estatísticas. Pela descrição feita nos artigos, 
não é possível deduzir como teria ocorrido precisamente a inserção da apresentação de Simmel nos debates, mas, dada a abrangência do temário da exposição, pode-se imaginar diálogos bastante plurais com os aspectos subjetivos sublinhados pelo autor. Foram esses, aliás, os traços da vida urbana cuja reflexão original do sociólogo berlinense instigou mais expressivas repercussões, permanecendo em diálogo com aspectos dos estudos urbanos, sobretudo do campo da antropologia e da história. Merece destaque a análise do autor sobre o predomínio do caráter intelectualista dos indivíduos na grande cidade, em oposição ao predomínio do sentimento na cidade pequena; resultante, segundo afirma, de certa forma subjetiva de proteção diante do desenraizamento instado pelas coações da vida urbana. (SIMMEL, 2005, p. 578) Ao concluir sua análise, observa um contraponto significativo na grande cidade: para ele, o progresso objetivo e material correspondeu ao retrocesso da cultura dos indivíduos em relação à espiritualidade, delicadeza e idealismo, deixando o indivíduo cada vez mais incapacitado para se sobrepor à cultura objetiva, rebaixando-se à quantidade negligenciável na qual predomina a impessoalidade. (SIMMEL, 2005, p. 588) Não deixa de ser significativa a atualidade dessas reflexões ao se considerar a paulatina expansão das formas de vida urbana - e monetária - nas décadas recentes.

Não seria sem interesse, para pensar o papel das pluralidades na apreensão do urbano, realizar-se um levantamento sobre os usos das reflexões simmelianas nos estudos sobre a cidade, mas certamente tal tarefa demandaria uma pesquisa que extrapola os objetivos destes apontamentos. Parece-me importante, porém, ter em mente ao menos três elementos desse legado acadêmico importante: primeiro, a dimensão sensível e subjetiva nele considerada; segundo, a relevância para os estudos urbanos da obra inicialmente publicada no Brasil na década de 1960 e presente de distintas maneiras; por fim, a inserção original do estudo sobre a grande cidade e a vida do espírito em um evento de caráter técnico e administrativo que visava discutir aspectos múltiplos da cidade no século XX. Parece-me constituir um exemplo significativo da pluralidade de saberes mobilizados e de questões abarcadas pelos estudos urbanos, bem como um sintoma das relações igualmente plurais e movediças entre os campos do conhecimento 272 voltados ao estudo da cidade. ${ }^{6}$ 
Talvez outra obra ainda mais emblemática para os estudos urbanos, especialmente aqueles voltados à cultura urbana em seus múltiplos aspectos, seja aquela de Walter Benjamin, outro autor cuja recepção e repercussão entre autores no Brasil mereceriam pesquisas aprofundadas em distintas áreas do conhecimento, na literatura, na sociologia, na filosofia, na história etc. ${ }^{7}$ No campo dos estudos históricos sobre a cidade, bem como em abordagens da história social e política, a obra, em certa medida, itinerante e pouco ortodoxa de Benjamin provocou significativas viragens - penso, por exemplo, na conformação no Brasil de uma área de estudos aproximando "cultura e cidade" ou nas importantes reflexões norteadas pela noção de "história a contrapelo", de inspiração benjaminiana. ${ }^{8}$ Não se trata, porém, de obra particularmente afeita a configurar o que se poderia chamar de "seguidores", dada sua ampla aderência a ousadias tanto interpretativas quanto temáticas e metodológicas, em certo sentido. Obras em si mesmas plurais, capazes de abordar elementos da poesia moderna, da literatura, de obras de arte em diferentes manifestações, da memória em suas tensas relações com a narrativa histórica, das metamorfoses de uma metrópole no XIX, entre outros recursos, os trabalhos de Benjamin ainda se valem de percursos e procedimentos que são, em si, experimentos interpretativos, como o uso de alegorias como forma de aproximação e elaboração, a ampla utilização de narrativas baseadas na memória e suas manipulações, ou o emprego de montagens e variantes em suas mais densas obras, como o trabalho das Passagens, obra inacabada que mereceu sua dedicação ao longo de 13 anos ao menos.

Para aproximar o caleidoscópio de estudos benjaminianos do fio condutor destes apontamentos - pensar o urbano a partir de pluralidades - e evitar, ao mesmo tempo, o risco de alguma desorientação diante de tantas possibilidades, busco ater-me à primeira versão do texto que apresenta o trabalho das Passagens, o "Exposé de 1935", "Paris, a capital do século XIX”. (BENJAMIN, 2007) Valendose de poemas, impressões, observações, excertos da dramaturgia e, sobretudo, de singular sensibilidade na leitura de elementos inscritos no cotidiano da metrópole, Benjamin (2007) toma como fio condutor uma tipologia de edificação comercial em Paris, as galerias de compras ou passagens, nas quais as vitrines assumem certo protagonismo 
na cena urbana, afetando-lhe as sensibilidades. Chama atenção a abordagem do "Fourier ou passagens", logo de início, observando-lhes características plurais como condições históricas para sua existência, como uma "conjuntura favorável do comércio têxtil" estimulando os magasins de nouveautés, a possibilidade artística de transformação desses espaços comerciais em espécies de galerias e uma condição tão objetiva quanto decisiva, inscrita na história da técnica e da arquitetura: a viabilidade de edificações em ferro como construção artificial. (BENJAMIN, 2007) O modo como entrelaça questões sociais, culturais, técnicas, artísticas e econômicas para problematizar um fenômeno urbano metropolitano mostra-se sem dúvida original, capaz de responder às demandas das novidades que busca descrever, e, ao mesmo tempo, trata-se de uma abordagem bastante exigente aos estudos urbanos, por motivos similares.

Um breve panorama dos tópicos visitados na Exposé pode permitir compreender a extensão e as articulações desse panorama complexo do século XIX parisiense, composto ao modo benjaminiano. São seis tópicos entrelaçados de modo a, paulatinamente, acrescer dimensões ao enquadramento, ampliando sua abrangência que, à primeira vista, parece precisa, ou seja, as passagens ou galerias comerciais cobertas de Paris: Fourier ou as passagens; Daguerre ou os panoramas; Grandville ou as exposições universais; Luís Felipe ou o intérieur; Baudelaire ou as ruas de Paris; Haussmann ou as barricadas. É o próprio Benjamin (2007) quem aponta uma narrativa cultural e política como pano de fundo para se apreender o entrelaçamento desses tópicos, sugerindo a ideia de Balzac de "ruínas da burguesia" e afirmando ter o desenvolvimento das forças produtivas arruinado os símbolos do desejo do século XIX, numa associação complexa de imagens, projeções e considerações de fundo econômico e social que, por certo, alteraram os referenciais para se pensar as grandes cidades no século XIX. Segundo afirma, o início desse processo se deu por meio dessas inversões enunciadas nos seis tópicos, pela arquitetura enquanto obra de engenharia, notadamente a arquitetura do ferro, seguida pela fotografia de panoramas enquanto reprodução da natureza, pela criação imaginária preparando-se para tornar-se prática enquanto arte gráfica a serviço da publicidade, e pela poesia enquanto 274 montagem no folhetim. 
Todos esses produtos estão prestes a oferecer-se ao mercado como mercadorias. Contudo hesitam ainda no limiar. Desta época, originam-se as passagens e os intérieurs, os pavilhões de exposição e os panoramas. São resquícios de um mundo onírico. ${ }^{9}$ (BENJAMIN, 2007, p. 51)

Willi Bolle, organizador das Passagens no Brasil e estudioso de Benjamin em suas leituras sobre o urbano, além de apontar essa flagrante discrepância entre progresso tecnológico e qualidade de vida social, formula um novo paradigma de análise ao sintetizar o pensamento sobre o fenômeno da metrópole como palco das transformações ocorridas a partir de meados do XIX, buscando não apenas retratar as mudanças na metrópole, mas tomá-la como "médium-de-reflexão", condição que compara à obra de arte capaz de proporcionar, como a metrópole para Benjamin, conhecimento crítico. Desse modo, pode-se dizer que a aproximação, melhor dizendo, as aproximações possíveis entre a obra de Benjamin e os estudos urbanos permitem não apenas multiplicar as entradas temáticas para se investigar a metrópole ou entrelaçar de modo mutuamente implícito tais entradas, mas também tomar a cidade como referência para renovados exercícios da própria narrativa histórica e do entendimento mesmo do urbano.

De modo alegórico, a grande cidade contemporânea é considerada um texto enigmático, criptografado, hieroglífico - dentro da tradição de Edgar A. Poe, o qual, em seu conto O homem da multidão, apresentou a metrópole como um texto escrito no limite da legibilidade. Pode-se dizer que Benjamin procurou decifrar esse texto durante a vida inteira, desde o livro de estreia, Rua de mão única, até seu projeto mais ambicioso, o das Passagens parisienses, ao qual deu mais tarde o título de Paris, capital do século XIX, e onde se propôs a escrever uma história social dessa cidade. (BOLLE, 2007, p. 98)

Tendo em mente as fundamentais reflexões potencializadas pelas obras de autores como Simmel e Benjamin, tomadas a um só tempo como exemplares de questões e abordagens plurais, ainda que singularmente delineadas, gostaria de retomar a percepção da obrigatória consideração sobre a pluralidade de saberes mobilizados para se 
apreender o urbano. Nota-se a insistente presença de aportes plurais mesmo quando restringimos a temporalidade abarcada e os campos do saber, como nesses exemplos. A impossibilidade de perseverar qualquer estabilidade quanto aos aportes teóricos e sistemas de conhecimento implicados nessas apreensões acrescenta ainda outros elementos, capazes de tornar mais complexa a consideração sobre o lugar e os efeitos dessa pluralidade. Parece-me significativo, nesse ponto, acompanhar algumas análises de dois campos do conhecimento que problematizaram o urbano: a filosofia e a própria história urbana, antes de se avançar para pensar o alcance de possíveis "abalos nos fundamentos" de estudos sobre o urbano quando se leva em conta as discussões em torno da crise de referenciais, que teriam colocado em xeque até mesmo a plausibilidade de "teorias da verdade".

Entendo ser importante sublinhar a relevância para os estudos sobre a cidade alguns autores, entre outros, cujo aporte teórico principal se apoia no pensamento filosófico. Além daqueles trabalhos mais recentes, como o do filósofo Luís Arenas, da Universidade de Zaragoza, em estudos sobre a cidade contemporânea (2011) e análises aproximando arquitetura e filosofia; o do antropólogo e filósofo Marcel Hénaff, da Universidade de San Diego, em trabalho instigante sobre a cidade futura (2014) e estudos sobre espaço público e democracia; destaco o estudo crítico de Otília Arantes (2001) sobre as relações entre ao colapso da modernização e os fins do urbanismo; e o estudo exaustivo dos autores belgas, o filósofo Pierre Ansay e o sociólogo René Schoonbrodt, na abrangente reunião de textos filosóficos das mais distintas tradições abordado a cidade, constituindo antologia essencial sobre o tema. (ANSAY; SCHOONBRODT, 1989) Cada um desses trabalhos é referenciado aqui como capaz de, a partir de pontos de vista plurais advindos do campo filosófico, iluminar questões sobre o urbano de modo bastante significativo, configurando-se, a meu ver, em referências importantes para estudos sensíveis a abordagens plurais do urbano.

No diálogo com a filosofia, porém, a despeito da importância de estudos como esses, parece-me incontornável a consideração das investigações da filósofa Françoise Choay, ainda que se possam apresentar reservas a algumas interpretações inclinadas a leituras esquemáticas, 276 sempre suscetiveis a limitações. Suas pesquisas exaustivas apoiadas 
no pensamento filosófico resultam em dois trabalhos capazes de colocar em pauta de modo bastante consistente as relações entre teorias e formas, entre pensamento político e linguagens técnicas em arquitetura e urbanismo. Parece-me tratar-se de um acréscimo às reflexões plurais sobre o urbano e as formas arquitetônicas que não mais permite, ao menos desde os anos 1960, a desconsideração de fundamentais preceitos político-filosóficos aos estatutos atuantes nas bases das decisões sobre a cidade e a vida urbana. $\mathrm{Na}$ antologia Urbanismo: utopias e realidades, originalmente publicada em 1965, Choay (1998, p. 2-3), afirma ter como objeto "as ideias que fornecem suas bases ao urbanismo" e apresenta não uma história desse campo de conhecimento, cuja configuração também é plural, mas "uma tentativa de interpretação" dessas ideias. A abordagem não estaria distante de A regra e o modelo, ${ }^{10}$ no qual Choay $(1985$, p. 3) adverte logo de início não se tratar de um livro sobre o espaço construído, o mundo concreto do urbano, a cidade, mas uma pesquisa que "deixa de lado os edifícios efetivamente construídos e trata apenas do espaço da cidade como coisa escrita". No estudo aprofundado do que denomina "textos realizadores e utopias", distingue os elementos teóricos e os pressupostos de tratados de arquitetura e de urbanismo, buscando inscrever no tempo as formas discursivas que os fundamentam. Podese, então, localizar a principal contribuição dessas abordagens para os estudos urbanos na possibilidade ímpar de trazer matéria à reflexão sobre a cidade, ainda que não se oriente pela materialidade urbana.

É significativo notar a quase simultaneidade de algumas publicações de algum modo inovadoras - ou capazes de introduzir diferentes aproximações - em torno da cidade e da história urbana, na década de 1960, mais ou menos próximas à antologia de Choay. Uma perspectiva cultural e interpretativa de grande fôlego, publicada por Lewis Mumford (1998) inicialmente em 1961, insere, de modo incisivo, as questões culturais nas investigações sobre as múltiplas ocorrências e transformações da cidade na história. Entre 1966 e 1968, são editadas ao menos quatro obras convertidas imediatamente em referências críticas fundamentais à problematização da cidade: Vittorio Gregotti (2001), com O território da arquitetura; Manfredo Tafuri (c1979), com Teoria e história da arquitetura, ambos ampliando o entrelaçamento entre pressupostos político-filosóficos e o estudo das transformações no campo da arquitetura; Aldo Rossi (1995), enfatizando a construção 
da cidade no tempo, atrelada aos valores sociais; e Robert Venturi (1995), com Complexidade e contradição em arquitetura, questionando, de modo decisivo, os diagnósticos e as soluções vistas como reducionistas da arquitetura de matriz modernista, cuja aposta em preceitos racionalistas teria antecipado seu declínio.

É expressivo o panorama que se vislumbra ao se colocar lado a lado essa produção crítica simultânea e de grande repercussão. Choay, Mumford, Gregotti, Tafuri e Venturi certamente introduzem não apenas perspectivas plurais e não lineares a certas questões em torno do urbano, mas, de modo geral, e cada qual a partir de seus pontos de embate, definem dimensões mais complexas e aprofundadas para se perscrutar a cidade. Estivessem isolados e não inseridos em contextos de discussões e desafios ao campo de estudos e ao mundo urbano, cada um desses trabalhos já seria, em si, potencialmente instigante para incentivar estudos urbanos em busca de origens e debates plurais na constituição do próprio temário de pesquisas e reflexões sobre a cidade. Rossi (1995, p. 3-6), por exemplo, refere-se à construção da cidade no tempo para ser possível apreender ela mesma como arquitetura, "como criação inseparável da vida civil e da sociedade em que se manifesta", e afirma estar exatamente nesse ponto a "natureza coletiva" da cidade, que lhe permite, enfim, incluir "o problema político da cidade", entendido como possibilidade de escolha - portanto, debate.

São perspectivas, de fato, nem sempre convergentes, que poderiam sugerir a um primeiro olhar não enquadramentos plurais, mas algum sedicioso relativismo ou mesmo algum capcioso pragmatismo cético. Porém, para além de investigações relativas ao próprio campo de estudos sobre a cidade - por si só pluridisciplinar, como se pretende também apontar nestas reflexões -, parece-me importante ampliar esse panorama para outras áreas, ainda que seja por ora apenas para alcançar algumas relações e diálogos possíveis, ou ainda acompanhar problematizações mais complexas, que não seria inadequado supor como problemática estarem direta ou indiretamente envolvidas, a despeito de nichos sempre persistentes nas áreas acadêmicas. Propõe-se aproximar, para efeito hipotético apenas, buscando compor importantes referenciais dessa ambiência crítica, estudos relativamente próximos 278 no tempo, formulados em outras áreas também entre os anos 1950 e 
1960, nem sempre próximas nas temáticas, mas com alguma relação possível, sobretudo considerando-se os questionamentos que realizam acerca dos limites das linguagens e representações, bem como das especificidades do conhecimento nas chamadas ciências humanas. Nos anos 1950, registra-se a circulação de algumas publicações, como A memória coletiva, de Halbwachs; História social da arte e da literatura, de Hauser; Origens do Totalitarismo e A condição humana, de Arendt; Empirismo e subjetividade, de Deleuze; O grau zero da escrita, de Barthes; Crítica e crise, de Koselleck; Tristes Trópicos, de Lévi-Strauss; História e verdade, de Ricoeur; A poética do espaço, de Bachelard; Cultura e sociedade, de Williams. Já na passagem para os anos 1960, How to Do Things with Words, de Austin; Arte e ilusão, de Gombrich; Mudança estrutural da esfera pública, de Habermas; As palavras e as coisas, de Foucault; Contra interpretação, de Sontag; Estrutura das revoluções científicas, de Kuhn.

Aspectos relativos às tensas relações entre linguagens e representações, entre culturas e interpretações, ou mesmo críticas, algumas agudas, às teorias da história e às apostas persistentes na racionalidade instrumental, como aquelas mobilizadas por Venturi, aparecem de diferentes maneiras nessa miríade de escritos. A onipotência dos conhecimentos científicos e da própria razão parece tensionada, nesse panorama, por uma pluralidade de formas, métodos, preceitos, viabilizando-se aberturas ao reconhecimento da importância de uma mudança de ênfase no papel da linguagem para compreender os processos múltiplos de fabricação de conhecimentos, entendimentos, significados. ${ }^{11} \mathrm{O}$ pluralismo, nesse conjunto, parece radicalizar-se e incidir sobre aquilo que se entendia como "verdadeiro", assumindo existir mais de uma forma de ser verdadeiro e trazendo à pauta, desse modo, a necessidade de se investigar pluralidades e lidar com referências plurais. Isso implica assumir que as histórias só podem ser múltiplas, em vez de falar de uma História única e unificada, com "h" maiúsculo, e seguramente também implica envolver - e deve ainda envolver os debates históricos e historiográficos em relações mais complexas. $\mathrm{Na}$ consideração dos pressupostos e enquadramentos, portanto, ao assumir-se a inserção dos estudos urbanos nesse contexto, parece-me inescapável a compreensão de certa relatividade do conhecimento, expressa tanto no chamado "giro linguístico", dos anos 1970, ele mesmo inteiramente conectado ao panorama de escritos acima alinhado, 
quanto nos chamados "giros culturais" pós e de-coloniais mais recentes. Não caberia explorar a potencialidade desses questionamentos e seus efeitos para os estudos urbanos, mas, a meu ver, pode ser instigante considerar as "profanações metodológicas" imagináveis quando o futuro do conhecimento é flexionado desse modo interrogativo.

\section{Pluralidade “Que Vem”}

Considerar os debates e acolher as instabilidades dos distintos campos do saber que problematizam a cidade, no meu entender, equivale a pensar por questões, a pensar com - e por meio de - pluralidades. A perspectiva plural, com isso, acena em favor do não linear, do não hegemônico, da consideração das lacunas, brechas, divergências, arenas em disputa. Implica acolher a incerteza - ou a "incerteza viva”, para lembrar o tema da 32a Bienal de São Paulo, em 2016, cuja proposta abarcava as relações entre os corpos e o ambiente, os organismos e os ecossistemas, incluindo o urbano de modo mais ou menos tenso. A ideia norteadora da mostra consistia em acolher a incerteza por entender o desconhecido como um espaço de jogo próprio ao campo das artes "enquanto a estabilidade é compreendida como uma cura para a angústia, a incerteza geralmente é evitada ou recusada". (VOLZ; REBOUÇAS, 2016, p. 20) A justificativa do evento assume, de início, a insistência histórica da arte em "vocabulários que permitem a ficção e a alteridade", reagindo à "incapacidade dos meios existentes de descreverem o sistema do qual fazemos parte" (VOLZ; REBOUÇAS, 2016) - pressupostos fundamentais para inserir a própria criação e apreensão artística na esfera da incerteza, do futuro e do passado interrogativos.

A incerteza na arte aponta para a criação, levando em conta a ambiguidade e a contradição. [...] A arte se funda na imaginação. E apenas através da imaginação seremos capazes de vislumbrar outras narrativas para o nosso passado e novos caminhos para o futuro. 'Incerteza viva' considera as incertezas como um sistema de orientação generativo e se constrói sobre a convicção de que, para enfrentar objetivamente as grandes questões do 
nosso tempo, como o aquecimento global e seu impacto em nossos habitats, a extinção de espécies e a perda da diversidade biológica e cultural, a crescente instabilidade econômica e política, a injustiça na distribuição dos recursos naturais da Terra, as migrações globais e a assustadora disseminação da xenofobia, é necessário desvincular a incerteza do medo. (VOLZ; REBOUÇAS, 2016, p. 20-21)

Não são reduzidas e tampouco suaves as provocações colocadas pelo evento, e certamente não caberia aqui avaliar as instigantes respostas obtidas e exibidas na mostra. Recolhe-se, na verdade, a indagação instigante sobre o poder da incerteza para aproximá-la aos estudos urbanos, na perspectiva da pluralidade delineada nestes apontamentos. Recorre-se novamente a Hénaff (2014), a partir de seus questionamentos igualmente provocativos sobre o futuro da cidade. Ao constatar o predomínio crescente do mundo urbano como forma de vida predominante no planeta, quando mais de metade dos habitantes de todas as partes pela primeira vez na história habitam áreas urbanas, o antropólogo e filósofo francês apresenta essas indagações: seria a cidade o futuro? Pode-se dizer que a forma urbana triunfou? Haveria um devir-cidade de todas as civilizações que faria da Terra um planeta urbano? E chama atenção para um paradoxo atual: exatamente no momento em que o mundo parece se tornar cidade, a cidade aparentemente deixa de ser um mundo, se pensarmos que a própria ideia de cidade parece dissolver-se, em parte por causa da extensão do espaço construído. (HÉNAFF, 2014, p. 12) Por meio dessas questões, são discutidas por ele duas hipóteses, explorando-se o conteúdo historicamente constituído nela implicadas: de início, pergunta-se se a dissolução da ideia de cidade deveria ser compreendida como uma evolução caótica, equivalente à perda de todo projeto arquitetônico e de toda exigência de organização do espaço urbano, ou seja, como fracasso irremediável; alternativamente, indaga-se a respeito de um possível novo paradigma que estaria para se evidenciar.

São interessantes as ponderações e análises estimuladas por tais questões, e a abertura que parecem contemplar - a acolhida da incerteza - permite discutir tanto elementos constitutivos do urbano, como 
o modelo de cidade concebido em numerosas culturas, quanto os resultados de uma observação sobre a configuração pouco vitalizadora do espaço público na cidade contemporânea. Nessa abordagem, é possível colocar em discussão certa apreensão linear do potencial da tecnologia e do progresso material como condição suficiente para a solução dos dilemas do urbano na atualidade, uma vez que permite desconstruir essa suposta linearidade inscrita no modelo de cidade como monumento - capaz de produzir um efeito singular -, como máquina - voltada à transformação, produção, organização - e como rede, na qual os eixos e dispositivos de circulação mantêm os fluxos e intercâmbios. Na análise do espaço público, é ampliada a discussão enquanto é confrontado o conceito mesmo de espaço público à disposição e ao tratamento dos edifícios públicos no espaço urbano, distintos das residências por sua visibilidade e função, ao mesmo tempo em que se investiga seu funcionamento como esfera de informação aberta e de debates livres - revisitando o ideal da pólis, do espaço comum aos cidadãos. É nesse ponto, aproximando as duas críticas, que se enfatiza, a partir do nível mais informal da experiência social na cidade, a importância de se reforçar a esfera comum, entendida como ordem estritamente local de relações citadinas em sua pluralidade.

Hénaff (2014, p. 67-68) propõe, como estratégia para fortalecer a esfera comum, abandonar a oposição público-privado e pensar o espaço comum a partir da rua, para assim instigar o reavivar do mundo urbano, pois entende ser a rua precisamente o lugar onde a diversidade humana encontra oportunidade de ser reconhecida e valorizada - daí sua importância crucial para se repensar o espaço público, o espaço comum na cidade: é aberto a todos, (re)conhecido por todos. A potência da forma visível da cidade, acompanhando-se esse raciocínio, não estaria no planejamento ou controle de suas formas, mas no recurso a um elemento político essencial, definidor da própria condição urbana, presente nas reflexões aqui discutidas a partir da dessemelhança aristotélica, do pluralismo kantiano, da condição humana arendtiana: a pluralidade humana entendida radicalmente como condição definidora da vida humana. A pluralidade como conditio sine qua non e conditio per quam da cidade. 


\section{NOTAS}

1 O verbete "ciudad", no dicionário A aventura das palavras da cidade através dos tempos, das linguas e das sociedades, organizado por Topalov, Bresciani, Coudroy de Lille e Rivière d'Arc (2014), apresenta uma ampla visão dos efeitos recíprocos da organização de cidades na América Hispânica, por exemplo. A versão integral do dicionário, com verbetes relacionados ao urbano, preparados a partir do uso em oito diferentes idiomas - alemão, espanhol, francês, inglês, italiano, português, russo, além do árabe -, amplia sobremaneira esse tipo de abordagem histórica do vocábulo. (TOPALOV et al., 2014)

2 A proposição kantiana de pensar a partir dessa possível pluralidade, considerando a espécie humana como um conjunto norteado por uma base comum, convergente quanto às questões morais e políticas, tem sido referenciada na proposta de uma orientação política para os povos em direção ao que denomina "paz perpétua" - denominação da obra publicada em 1795. A proposta de um "direito cosmopolita" ou "direito das gentes", baseada no aprimoramento da razão individualmente e na referência ao todo, é fundamental nessa obra, também apoiada nos princípios da pluralidade, bem como em "A ideia de história universal a partir de um ponto de vista cosmopolita”, de 1784.

3 Agradeço à generosa ajuda de Lílian do Valle, professora de Filosofia da Educação da Universidade do Estado do Rio de Janeiro (UERJ), ao buscar precisar o contexto da afirmação atribuída por Sennett a Aristóteles, muitas vezes repetida entre os estudos urbanos. Utilizada como epígrafe em Carne e pedra ("Uma cidade é construída por diferentes tipos de homens; pessoas iguais não podem fazê-la existir.”), aparentemente aponta para uma interpretação mais ou menos livre de duas ideias importantes da política, quando o filósofo distingue a unidade do território e a unidade da pólis, constituída pela participação em comum de seus cidadãos. "É preciso que a polis seja, como já se disse anteriormente, uma multiplicidade feita una e comunitária por via da educação.” (livro II, 1263 b 35).

4 Os exemplos remetem às seguintes obras: de Engels (2008, 2015), editadas respectivamente em 1843 e 1875, ambas voltadas a investigações e preocupações a respeito da moradia de trabalhadores em cidades industriais da Inglaterra; de Gustave Le Bon (2008), de 1895, que se indaga a respeito dos possíveis riscos do comportamento das multidões à coesão social; o trabalho de 1903, preparado por Simmel (2005) a partir do livro publicado alguns anos antes, Filosofia do dinheiro; e em meio a uma múltipla e singular produção sobre a cultura sob a modernidade, o trabalho original das Passagens de Benjamin (2007).

5 A coletânea $\mathrm{O}$ fenômeno urbano figurou como referência às leituras sobre o urbano em perspectiva sociológica, reunindo, além do texto do sociólogo berlinense, artigos de autores fundamentais para a consolidação da sociologia 
urbana, como Louis Wirth, ex-aluno de Simmel, em "O Urbanismo Como Modo de Vida”, de 1938; Robert Erza Park em "A Cidade: sugestões para a investigação do comportamento humano no meio urbano", de 1915; "Conceito e categoria da cidade”, de 1911-1913, de Max Weber. O estudo de Simmel sobre a vida nas grandes cidades recebeu anos depois, em 2005, nova tradução a partir do original em alemão, alterando alguns conceitos e o próprio título.

6 A coletânea organizada por Pechman (2014) a partir de evento sobre Simmel e os estudos urbanos atualiza e amplia parte das questões aqui sugeridas.

7 Há um dossiê da Revista da USP (n. 15, 1982) especialmente dedicada a Benjamin no Brasil, bem como o interessante estudo de Gunter Pressler (2006) sobre as leituras de Benjamin em meio à formação da intelectualidade no país.

8 Sobre a importância dessa aproximação entre "cultura e cidade" nos estudos de história urbana, ver trabalho publicado por Cerasoli em parceria com Marisa Carpintéro (2009), bem como as reflexões de Bresciani (2002) em que retoma e reelabora estudo que tem sido referência para investigações históricas do urbano, a partir da metáfora das sete portas como entradas conceituais na cidade; sobre a "história a contrapelo", como exemplo e homenagem, registro o trabalho seminal De Decca (1981), entrelaçando memória, história e política.

9 Na segunda versão da Exposé, de 1939, essas imagens oníricas associadas ao que denomina de reconhecimento dos monumentos da burguesia como ruínas antes mesmo de seu desmoronamento, figuradas como fantasmagorias, pois o século, para ele, não teria conseguido responder às virtualidades técnicas com uma nova ordem social.

10 Apresentado como tese em 1978.

11 As reflexões de Feyerabend (2010) sobre a relatividade e a necessidade de consideração consequente da diversidade de culturas, também no campo científico, parecem-me muito importantes no aprofundamento desse panorama e desse debate. 


\section{REFERÊNCI IS}

ANSAY, P.; SCHOONBRODT, R. Penser la Ville: choix de textes philosophiques. Bruxelles: Aux Archives d'Architecture Moderne, 1989.

ARANTES, O. Urbanismo em fim de linha e outros estudos sobre o colapso da modernização arquitetônica. 2. ed. São Paulo: EDUSP, 2001.

ARENAS, L. Fantasmas de la vida moderna: ampliaciones y quiebras del sujeto en la ciudad contemporanea. Madrid: Trotta, 2011.

ARENDT, H. A condição humana. Tradução de Roberto Raposo. 10. ed. Rio de Janeiro: Forense Universitária, 2004.

ARGAN, G. C. História da arte como história da cidade. 3. ed. Tradução de Pier Luigi Cabra. São Paulo: Martins Fontes, 1995.

ARISTOTE. Euvres complètes. Tradução de Pierre Pellegrin. Paris: Flammarion, 2014.

BENJAMIN, W. Passagens. Belo Horizonte: Ed. UFMG; São Paulo: Imprensa Oficial do Estado de São Paulo, 2007.

BOLLE, W. A metrópole como médium-de-reflexão. In: SELIGMANNSILVA, M. (Org.). Leituras de Walter Benjamin. 2. ed. São Paulo: Annablume, 2007. p. 89-109.

BRESCIANI, M. S. M. Cidade e história. In: OLIVEIRA, L. L. (Org.). Cidade: história e desafios. Rio de Janeiro: Ed. FGV, 2002. p. 16-35.

CARPINTÉRO, M. V. T.; CERASOLI, J. F. A cidade como história. História: questões \& debates, Curitiba, v. 50, n. 1, out. 2009. Disponível em: <http:// revistas.ufpr.br/historia/article/view/15672>. Acesso em: 20 nov. 2011.

CHOAY, F. A regra e o modelo: sobre a teoria da arquitetura e do urbanismo. Tradução de Geraldo Gerson de Souza. São Paulo: Perspectiva, 1985.

CHOAY, F. O urbanismo: utopias e realidades - uma antologia. Tradução de Dafne Nascimento Rodrigues. 5. ed. São Paulo: Perspectiva, 1998. 
DE DECCA, E. S. 1930: o silêncio dos vencidos. São Paulo: Brasiliense, 1981.

DIDEROT, D.; D'ALEMBERT, J. R. Verbetes politicos da enciclopédia.

Tradução de Maria das Graças de Souza. São Paulo: Editora da UNESP:

Discurso Editorial, 2006.

ENGELS, F. A situação da classe trabalhadora na Inglaterra. Tradução de B.

A. Schumann. São Paulo: Boitempo, 2015.

ENGELS, F. Sobre a questão da moradia. Tradução de Nélio Schneider.

São Paulo: Boitempo, 2008.

FEYERABEND, P. K. Adeus à razão. Tradução de Vera Lucia Joscelyne. São Paulo: Editora da UNESP, 2010

GOMES, M. F. de M. Ética e direito: a consciência da virtude em "Ética a Nicômacos”. 2. ed. Belo Horizonte: Initia Via, 2013.

GREGOTTI, V. Território da arquitetura. Tradução de Berta Waldman-Villa; Joan Villa. 3. ed. São Paulo: Perspectiva, 2001.

HÉNAFF, M. La ciudad que viene. Tradução de Paola J. Aponte et al. Santiago de Chile: LOM, 2014.

KANT, I. Antropologia de um ponto de vista pragmático. Tradução de Célia A. Martins. São Paulo: Iluminuras, 2006.

LE BON, G. Psicologia das multidões. Tradução de Mariana Sérvulo da Cunha. Rio de Janeiro: F. Briguiet, 2008.

MUMFORD, L. A cidade na história: suas origens, transformações e perspectivas. Tradução de Neil R. da Silva. 4. ed. São Paulo: Martins Fontes, 1998.

PECHMAN, R.M. (Org.). A pretexto de Simmel: cultura e subjetividade na metrópole contemporânea. Rio de Janeiro: Letra Capital, 2014.

PRESSLER, G. K. Benjamin, Brasil: a recepção de Walter Benjamin, de 1960 a 2005: um estudo sobre a formação da intelectualidade brasileira. São Paulo: Annablume, 2006.

ROSSI, A. Arquitetura da cidade. Tradução de Eduardo Brandão.

28 G São Paulo: Martins Fontes, 1995. 
SENNETT, R. Carne e pedra: o corpo e a cidade na civilização ocidental. Tradução de Marcos Aarão Reis. 2. ed. Rio de Janeiro: Record, 2001.

SIMMEL, G. As grandes cidades e a vida do espírito (1903). Mana, Rio de Janeiro, v. 11, n. 2, p. 577-591, 2005.

TAFURI, M. Teorias e história da arquitetura. Tradução de Ana Brito; Luis Leitão. Lisboa: Presença, c1979.

TOPALOV, C. et al. (Org.). A aventura das palavras da cidade através dos tempos, das linguas e das sociedades. São Paulo Romano: Guerra, 2014.

TOPALOV, C. et al. (Dir.). L'Aventure des mots de la ville: a travers le temps, les langues, les sociétés. Paris: Robert Laffont, 2010.

VENTURI, R. Complexidade e contradição em arquitetura. Tradução de Álvaro Cabral. São Paulo: Martins Fontes, 1995.

VELHO, O. G. (Org.). O fenômeno urbano. Rio de Janeiro: Zahar, 1967.

VOLZ, J.; REBOUÇAS, J. (Org.). Guia 32a Bienal de São Paulo: incerteza viva: guia. São Paulo: Fundação Bienal de São Paulo, 2016.

WAIZBORT, L. As aventuras de Georg Simmel. São Paulo: Ed. 34, 2000.

WAIZBORT, L. Simmel no Brasil. Dados, Rio de Janeiro, v. 50, n. 1, p. 11-48, 2007. Disponível em: <http://www.scielo.br/scielo.php?script=sci_ arttext\& pid=S0011-52582007000100002\&lng=en\& $\&$ rm=iso>. Acesso em: 20 out. 2016.

WOODHEAD, H. The First German Municipal Exposition. (Dresden, 1903). American Journal of Sociology, Chicago, v. 9, n. 4, p. 433-458, jan. 1904a. Disponível em: <http://www.jstor.org/stable/2762173>. Acesso em: 20 out. 2016.

WOODHEAD, H. The First German Municipal Exposition. (Dresden, 1903). American Journal of Sociology, Chicago, v. 9, n. 5, p. 612-630, Mar. $1904 b$. Disponível em: <http://www.jstor.org/stable/2762101>. Acesso em: 20 out. 2016.

WOODHEAD, H. The First German Municipal Exposition. (Dresden, 1903). American Journal of Sociology, Chicago, v. 9, n. 6, p. 812-831, May 1904c. Disponível em: <http://www.jstor.org/stable/2762093>. Acesso em: 20 out. 2016. 